\title{
Supply Chain Contract Model with Vague Demand Information
}

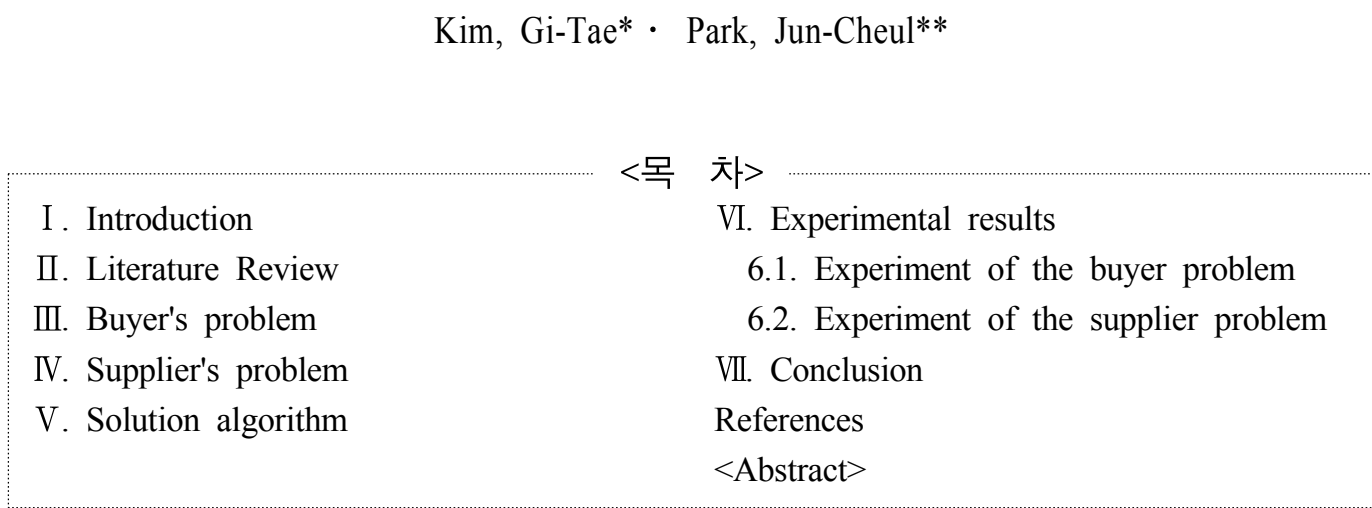

\section{I . Introduction}

In supply chain, among many sectors, a wholesaler or retailer as a buyer purchases the finished product from the manufacturer as a supplier and sells them to customers. The problem between these two sectors has been an important issue. The buyer prefers the flexible order quantities to meet the demand of customers while the supplier wants the fixed orders to make the stable production plan (Frascatore and Mahmoodi, 2008).
This conflict can be resolved by the contract between the buyer and the supplier (Cachon, 2003). This paper formulates the supply chain contract model with flexible options and fuzzy random variables.

Information between the buyer and the supplier may be shared well or not. The information has been important part in supply chain management (Moon and Kang, 2008; Cho et al. 2007; Suh et al. 2003). In real environment, the buyer and the supplier do not want to share the information each other unless they have had a good relationship for a long time. However,

* Researcher, Kansas State University, gitaekimemail@gmail.com, First Author

** Associate professor, Department of Industrial Information and Management Engineering, GangneungWonju National University, jcking@gwnu.ac.kr, Corresponding Author 
the contract can be made even if they are new buyer or supplier.

There are several contract types between a buyer and a supplier (Cachon, 2003). Among them, quantity flexibility contract has been widely used to reduce the risk of fluctuation of demand. This paper considers a decentralized system that the buyer and the supplier aim to achieve their own optimal solutions in two time period. The contract has an option that adjusts the order quantities after the buyer observes the demand revealed.

Due to the uncertainty of customer demand, stochastic programming has been used for the supply chain contract model such as a newsvendor model (Xiong et al., 2011). The stochastic programs has variables that represent the uncertainty in the objective function or constraints. In addition to that, stochastic programs can make a decision over time period and have been successful for the supply chain models. The variables under uncertainty are described by the probability. The stochastic programs assumes that the probability distribution of the variable is known. The probability distribution is usually derived from the history data. However, when there is lack of history data or the information of data is vague, the stochastic programs is not appropriate (Chen and Ho, 2011). In this case, experience and managerial subjective judgment is rather accurate. Therefore we apply fuzzy set theory to give the representation for those variables
(Zimmermann, 1991).

This paper proposes the supply chain contract model with fuzzy linear programs for the buyer and the supplier. Demand of customers is characterized with fuzzy random variables. The problem in this research has single buyer and supplier, single commodity, and two time period. The option in the contract is the right of the buyer to be able to reduce or increase the order quantity at the beginning of the second time period after observing the demand revealed. With the option contract, the buyer can respond flexibly to the fluctuated customer demand and the supplier can set up more stable production plan. Although reducing the variability of manufacturing in the supplier is an important issue, the paper focuses on the supply chain contract model to consider the coordination between the buyer and the supplier to resolve the uncertainty arising from the customer demand.

For example, the buyer may forecast the demand is 100 in period 1 and 100 in period 2. At the beginning of period 1 , the buyer purchases 200 finished products from the supplier. The 100 finished products are delivered to the buyer at the beginning of period 1 . The last 100 finished products are supposed to be delivered at the beginning of period 2. However, the demand of customers is uncertain and vague. If the demand in period 1 is 70 , the buyer wants to reduce the amount of purchase for period 2 . On the other hand, if the demand in period 1 
is 130 , the buyer prefers to increase the amount of purchase for period 2. The option enables the buyer to adjust the amount of purchase within a certain capacity.

The paper is organized as follows. In section $\Pi$, we describe the literature review for the supply chain contract using fuzzy set theory. The mathematical models for the buyer and the supplier are presented in section III and section IV. The solution algorithm is presented in section V. Section VI shows the experimental results. In the conclusion, we review the research of this paper.

\section{Literature review}

Supply chain literature of the interaction between two actors which are a buyer and a supplier often focuses on the contracts to coordinate the supply chain (Simchi-Levi and Kaminsky, 2003). There are a number of contract types (Cachon, 2003). The wholesale price contract is that the supplier merely charges the retailer a fixed wholesale price per unit ordered. The buy back contract is that the supplier charges the retailer the price per unit purchased, but pays the retailer the cost per unit remaining at the end of the season. The revenue sharing contract is that the supplier charges the price per unit purchased plus the retailer gives the supplier a percentage of his revenue. The quantity flexibility contract is that the supplier charges the price per unit purchased but then compensates the retailer for his losses on unsold units. The sale rebate contract is that the supplier charges the price per unit purchased but then gives the retailer an rebate per unit sold above a threshold. There are many types of quantity discount contract. One technique to obtain coordination is to choose the payment schedule such that the retailer's profit equals a constant fraction of the supply chain's profit.

Some researches for supply chain contracts are based on the fuzzy set theory. Sanders et al. (1993) deals with the problem of the assessment of natural resources as a Fuzzy Logical Optimization (FLO). Supply options, e.g., water, mineral, food or energy, can be matched to the various demand centers, which is considers as a fuzzy logistical optimization problem. The results are obtained by applying the Maximum-minimum Rule of fuzzy set theory. Petrovic et al. (1998) develops the supply chain fuzzy models and the supply chain simulator for the isolated inventory to analyze dynamic behavior of a serial supply chain in an uncertain environment. Customer demand and external supply of raw material were represented by fuzzy sets. Discrete fuzzy sets are used to model various kinds of uncertainty in customer demand and external supply, demonstrating their conceptual and computational simplicity. $\mathrm{Hu}$ et al. (2001) give a bidding decision model in multiagent supply chain of Contract Net Protocol (CNP). Maximum sales rate of product in each 
period is a fuzzy parameter which has a membership grade function. They make the problem to the chance constrained stochastic programming problem and solve it with heuristic method of generic algorithm. Bjork and Carlsson (2005) propose A new model of the Economic Order Quantity with backorders and fuzzy lead times. They focus on the effect of flexibility in lead times on the distributors, which are in the middle of the supply chain. The lead times are defined as triangular fuzzy numbers. Peng and Chen (2005) make a model of the supply chain flexibility based on supply contract. They apply fuzzy set theory to give the representation for variables with uncertainty of the supply lead time and demand quantity. Dutta et al. (2005) propose a single period inventory model as the classical newsboy problem. The demand data are imprecise with fuzzy probability as triangular fuzzy number. They find a defuzzified representative of the unique fuzzy number. $\mathrm{Li}$ and Zhao (2006) suggest a buyback contract model with fuzzy random demand. They studies response method of the buyback contract with demand information updating. The supplier and the retailer can adopt pessimistic, optimistic and risk neutral decision criteria when facing fuzzy random demand. Arshinder et al. (2007) introduce a model to measure the effect of the supply chain coordination using fuzzy logic. The coordination mechanisms are assessed to evaluate the score for the extent of coordination. Each linguistic term has a range of assessment scores, which can be described in triangular membership function form, rather than a single value. When a range of terms is used, a trapezoidal equivalent of the triangular membership functions representing the range of linguistic terms is derived before the conversion formula is applied. Hall et al. (2007) formulate the climate change model with incomplete knowledge of input information.

They represent scenarios of greenhouse gas emissions as fuzzy sets on the basis that scenarios are linguistic constructs, which, nonetheless contain some ordering of the possibility of different emissions trajectories materializing within a given scenario. They also illustrate how non-additive measures provide a flexible framework for aggregation of scenarios. Delft and Vial (2004) proposed the supply chain contract model based on scenarios considering multiple time periods. Wang et al. (2008) considered the revenue sharing contract with fuzzy demand. Sang et al. (2010) suggested the two stage stochastic programming model of return contract with fuzzy demand. Wang et al. (2009) proposed a single period and long term contract model with fuzzy market demand.

Cachon (2003) identified that it is hard which contract should be adopted over another. The quantity flexibility contract has been widely studied by researchers and can provide the coordination of the supply chain. When the demand information is vague, the stochastic programming model may not be appropriate. 
Upon this environment, the fuzzy set theory is useful to express the demand. Recently, an option has been used in the supply chain contract model to adjust amount of contract materials such as quantity, price, and other services. In this respect, the model in this research combines the fuzzy set theory into the quantity flexibility contract with an option.

This paper proposes the quantity flexibility contract model with a fuzzy linear program with options that are used to adjust the order quantity of the buyer at the end of the second period. We considers single buyer and single supplier that have their optimization model. The method of defuzzification in this paper is the graded mean integration representation (Chen, 1998).

\section{Buyer's problem}

The buyer, as a retailer or wholesaler, purchases the finished products from the supplier and sells them to end customers. This paper considers single buyer, single supplier, single commodity, and two time period. We assume that the initial inventory is zero and the probability distribution of the demand of customers is unknown. In order to get a discount arising from large amount of order, the buyer purchases the finished products from the supplier for two time period at the beginning of the first time period and the products are delivered period 1 and 2 separately.
Due to the uncertainty of demand, the buyer may adjust the order quantity at the beginning of period 2 after observing the demand of customer revealed in period 1 . This adjustment can be conducted by the contract with the supplier. The contract is a type of quantity flexibility one. The buyer purchases an option from the supplier at the beginning of period 1 . The option in the contract is the buyer's right to order additional quantities or to reduce the quantities for period 2 at the beginning of period 2. The buyer may exercise the option or not, depending on the demand revealed.

Therefore, the buyer purchases the finished products as well as the option from the supplier at the beginning of period 1 . At the end of period 1 , the buyer observes the demand and makes a decision of exercising the option or not. The goal of the buyer is to maximize the expected profit which is the revenue minus expenses.

We formulated the buyer's problem with a linear programming model with fuzzy random variable. In this model, the only uncertainty is the demand of customers. Stochastic programming assumes the probability distribution of uncertainty is known. However, sometimes, the probability distribution of uncertainty may be vague or incorrect in reality. Instead, the estimation of the expert can be appropriate such as "demand is about 100" or "demand is not less than 90" or "demand is not greater than $110 "$. Fuzzy set theory is helpful to describe this situation. 
Assume that demand is a triangular fuzzy number, the fuzzy number is LR type, and the fuzzy set is normal. Let $D$ be the fuzzy set for demand as

$$
D=\left\{\left(\widetilde{d}_{1}, \pi_{1}\right),\left(\widetilde{d}_{2}, \pi_{2}\right),\left(\widetilde{d}_{3}, \pi_{3}\right), \ldots,\left(\widetilde{d}_{n}, \pi_{n}\right)\right\}
$$

, where $\pi_{i}, i=1, \ldots, n$ is the fuzzy probability corresponding to the fuzzy demand number $\widetilde{d}_{i}$.

Triangular fuzzy variables for each demand are denoted by $d_{i}^{l}, d_{i}^{m}$, and $d_{i}^{h}$ which present three scenarios: low, medium, and high demand of customers. Their fuzzy probabilities are $\pi_{i}^{l}$, $\pi_{i}^{m}$, and $\pi_{i}^{h}$, respectively. The membership function of the demand is as follows.

$$
\mu_{D}(x)=\left\{\begin{array}{cl}
\frac{\left(x-d_{l}\right)}{d_{m}-d_{l}}, & \text { if } d_{l} \leq x \leq d_{m} \\
\frac{\left(-x+d_{h}\right)}{d_{h}-d_{m}}, & \text { if } d_{m} \leq x \leq d_{h} \\
0 & , \text { otherwise }
\end{array}\right.
$$

where $x \in D$ is the fuzzy variable for demand.

The definition of variables and parameters of the buyer's model are shown as below.

\section{Variables}

$X_{1}$ : number of options to purchase at the beginning of period 1

$Y_{1}$ : number of options to exercise at the beginning of period 2

$Q_{1}, Q_{2}$ : order quantities at the beginning of period 1 and 2

$I_{1}, I_{2}$ : inventory of finished products at the end of period 1 and 2

$I_{1}^{+}, I_{2}^{+}$: physical inventory of finished products at the end of period 1 and 2

$I_{1}^{-}, I_{2}$ : back order of finished products at the end of period 1 and 2

\section{Parameters}

$h_{1}, h_{2}$ : holding costs per unit of finished products in period 1 and 2

$s_{1}, s_{2}$ : selling prices per unit of finished products in period 1 and 2

$r_{1}, r_{2}$ : shortage costs per unit of finished products in period 1 and 2

$p_{1}, p_{2}$ : purchasing costs per unit of finished products in period 1 and 2

$o_{1}:$ option price per unit of the option in period 1 and 2

$e_{1}$ : exercise price per unit of the option in period 1 and 2

$v$ : salvage price per unit of the finished products in period 2

$X_{\text {m ax }}$ : maximum number of options to purchase in each period

The fuzzy linear programming model for the buyer is as follows.

$$
\begin{aligned}
& \operatorname{Max} E(f(Q, X, Y, I)) \cdots \cdots \cdots \cdots \cdots \cdots \cdots \cdots \cdots \cdot(2) \\
& \text { s.t. } I_{1}=I_{1}^{+}-I_{1}^{-} \\
& I_{2}=I_{2}^{+}-I_{2} \\
& I_{1}=Q_{1}-\widetilde{d}_{1} \\
& I_{2}=I_{1}+Q_{2}+Y_{1}-\widetilde{d}_{2}
\end{aligned}
$$




$$
\begin{aligned}
& -X_{1} \leq Y_{1} \leq X_{1} \\
& X_{1} \leq X_{\max } \\
& I_{1}^{+} \geq 0, I_{1} \geq 0, I_{2}^{+} \geq 0, I_{2} \geq 0 \cdots \cdots(9) \\
& Q_{1} \geq 0, Q_{2} \geq 0, X_{1} \geq 0
\end{aligned}
$$

The objective of the buyer's model is to maximize the expected profit that is considered as subtracting expenses from revenues.

The revenue of the buyer is as follows.

$$
\begin{aligned}
& f(Q, X, Y, I)= \\
& \text { Revenue-Expenses }
\end{aligned}
$$

The revenue of the buyer is as follows.

$$
\begin{aligned}
& \text { Revenue }= \\
& s_{1}\left(\widetilde{d}_{1}-I_{1}\right)+s_{2}\left(\widetilde{d}_{2}+I_{1}^{-}-I_{2}\right)+v I_{2}^{+}
\end{aligned}
$$

The first and second terms in equation (12) are the revenue from the sales in period 1 and 2. We assume there is no backlog at the beginning of the period 1. The last term is that the buyer can return the leftover finished products to the supplier with salvage price at the end of period 2. The expenses of the buyer have three terms of costs as follows.

$$
\begin{aligned}
& \text { Expenses }= \\
& \text { option }+ \\
& \text { inventory }+ \\
& \text { purchasing proucts }
\end{aligned}
$$

$$
\text { Option costs }=o_{1} X_{1}+e_{1} Y_{1}
$$

Inventory costs $=h_{1} I_{1}^{+}+h_{2} I_{2}^{+}+r_{1} I_{1}^{-}+r_{1} I_{2}^{-}$

Purchasing costs $=p_{1} Q_{1}+p_{2} Q_{2} \cdots$
Constraints (3) and (4) present the inventory separated into the physical and the backlog. In constraint (5), the period 1 inventory is the order quantity minus the demand on the first period because of the assumption of no inventory at the beginning. Constraint (6) shows the period 2 inventory. Constraint (7) denotes the bound of option that can be a negative value. If the exercised option value is negative, the buyer can reduce the order quantity for period 2 . If the exercised option value is positive, the buyer can order additional quantities. Depending on the capacity of the supplier, the option can be sold up to the maximum amount represented by $X_{\max }$. Constraint (8) presents the maximum limit of the option that the buyer can purchase. The goal of this problem is to maximize the expected profits with fuzzy random demand.

\section{Supplier's problem}

The supplier, as a manufacturer, produces finished products and sells them to the buyer. To produce the finished products, the supplier purchases the raw materials from upstream supplier. Like the finished product in the buyer model, raw materials are purchased for two periods at the beginning of period 1 and are separately delivered in period 1 and 2 without refilling. We assume that the supplier meets all demand from the buyer.

The supplier purchases raw materials for two 
time period. At the beginning of period 1 , the supplier produces the finished product, sells the products and options to the buyer. Depending on the demand of customers, the supplier may produce more or fewer finished products for period 2. At the end of period 2, the supplier should purchase the leftover products from the buyer with salvage price. The supplier can also sell the leftover raw materials to upstream supplier.

The goal of the supplier problem is to maximize the expected profit. The model is similar to the buyer problem as follows.

Variables

$M_{1}, M_{2}$ : amount of raw materials issued at the beginning of period 1 and to be delivered in period 1 and 2 , respectively

$Z_{1}, Z_{2}$ : amount of production at the beginning of period 1 and 2

$I_{1}^{r}, I_{2}^{r}$ : inventory for the raw materials at the end of period 1 and 2

$I_{1}^{f}, I_{2}^{f}$ : inventory for finished products at the end of period 1 and 2

\section{Parameters}

$v^{f}$ : unit salvage value of finished products

$v^{r}$ : unit salvage value of raw materials

$u$ : return cost of leftover finished products from the buyer

$t$ : extra unit transportation cost of leftover returned finished product from the buyer
$X_{1}^{b}:$ number of options purchased by the buyer in period 1 and 2

$Y_{1}^{b}:$ number of options exercises by the buyer at the end of period 1

$Q_{1}^{b}, Q_{2}^{b}$ : order quantities purchased by the buyer in period 1 and 2

$o_{1}$ : option price per unit of the option in period

1 and 2

$e_{1}$ : exercise price per unit of the option at the end of period 1

$p_{1}, p_{2}$ : selling price per unit of finished products

$c_{1}$ : purchasing cost per unit of raw material in period 1

$w_{1}, w_{2}$ : unit labor costs of production for an order in period 1 and 2

$h_{1}^{f}, h_{2}^{f}$ : unit holding costs for finished products in period 1 and 2

$h_{1}^{r}, h_{2}^{r}$ : unit holding costs for raw materials in period 1 and 2

$I_{2}^{b}$ : physical finished products inventory from the buyer at the end of period 2

The fuzzy linear programming model for the supplier is as follows.

$$
\begin{aligned}
\operatorname{Max} & E(g(M, Z, I)) \\
\text { s.t. } & I_{1}^{r}=M_{1}-Z_{1} \\
& I_{2}^{r}=I_{1}^{r}+M_{2}-Z_{2} \\
& I_{1}^{f}=Z_{1}-Q_{1}^{b} \ldots \ldots \ldots . .
\end{aligned}
$$




$$
\begin{aligned}
& I_{2}^{f}=I_{1}^{f}+Z_{2}-Y_{1}^{b}-Q_{1}^{b} \\
& I_{1}^{r} \geq 0, I_{2}^{r} \geq 0 \\
& M_{1} \geq 0, M_{2} \geq 0 \ldots \ldots \ldots \ldots \ldots \ldots \ldots \ldots \ldots \\
& Z_{1} \geq 0, Z_{2} \geq 0
\end{aligned}
$$

The objective of the supplier's problem is also to maximize the profit. The profit is considered as subtracting expenses from revenues.

$g(M, Z, I)=$ Revenue - Expenses $\cdots$

The revenue of the supplier is as follows.

$$
\begin{aligned}
& \text { Revenue }= \\
& p_{1} Q_{1}^{b}+p_{2} Q_{2}^{b}+e_{1} Y_{1}^{b}+ \\
& o_{1} X_{1}^{b}+v^{r} I_{2}^{r}+v^{f}\left(I_{2}^{f}+I_{2}^{b}\right)
\end{aligned}
$$

In (26), the first two terms are sales of finished products in period 1 and 2. The third term is for the exercised option and the fourth is the sales of option to the buyer. The last three terms are for salvage values of inventory of raw materials, finished products, and returned finished products. This inventory is assumed to be sold in the external market. The expenses of the supplier is as follows.

$$
\begin{aligned}
& \text { Expenses }= \\
& \text { Inventory }+ \\
& \text { production and purchase }+ \text { return } \\
& \text { Inventory }= \\
& h_{1}^{r} I_{1}^{r}+h_{2}^{r} I_{2}^{r}+h_{1}^{f} I_{1}^{f}+h_{2}^{f} I_{2}^{f} \\
& \text { Production and purchase }= \\
& w_{1} Z_{1}+w_{2} Z_{2}+c_{1}\left(M_{1}+M_{2}\right) \\
& \text { Return }=(u+t) I_{2}^{b}
\end{aligned}
$$

The expenses of inventory consists of holding costs for raw materials and finished products for period 1 and 2. In (29), production costs are labor costs for the amount of productions and the raw materials for both time period are purchased at the beginning of period 1 . The return in (30) requires the purchasing and extra transportation costs for the leftover inventory from the buyer.

The constraints (18) and (19) present the inventory of raw materials in period 1 and 2 . The inventory of finished products for each period are shown in the constraints (20) and (21). The constraints (22), (23), and (24) denote the nonnegativity of variables.

\section{Solution algorithm}

The only uncertainty of the model in this paper is the demand of customers. The demand has three scenarios as defined in section 3: low, medium, and high. For the decision making, a unique fuzzy value is required. This paper adopted the graded mean integration representation for defuzzfication (Chen, 1998; Chen and Wang, 2001).

Assume that the expected profits for each scenario of demand in the buyer or supplier model are $E P_{l}, E P_{m}$, and $E P_{h}$. From the membership function (1) of the demand, the membership function of the expected profits are derived as follows. 
Table 1. Data set of demand

\begin{tabular}{|c|c|c|c|c|c|c|}
\hline \multirow{2}{*}{ Levels } & \multicolumn{3}{|c|}{ Period 1 } & \multicolumn{3}{c|}{ Period 2 } \\
\cline { 2 - 7 } & Low & Medium & High & Low & Medium & High \\
\hline 1 & 500 & 1000 & 1440 & 500 & 1000 & 1660 \\
\hline 2 & 599 & 1000 & 1266 & 599 & 1000 & 1266 \\
\hline 3 & 733 & 1000 & 1533 & 733 & 1000 & 1533 \\
\hline 4 & 866 & 1000 & 1133 & 866 & 1000 & 1133 \\
\hline 5 & 899 & 1000 & 1033 & 933 & 1000 & 1066 \\
\hline 6 & 800 & 1000 & 1300 & 900 & 1000 & 1200 \\
\hline
\end{tabular}

$$
\mu_{E P}(x)=\left\{\begin{array}{cl}
\frac{\left(x-E P_{l}\right)}{E P_{m}-E P_{l}}, & \text { if } E P_{l} \leq x \leq E P_{m} \\
\frac{\left(-x+E P_{h}\right)}{E P_{h}-E P_{m}}, & \text { if } E P_{m} \leq x \leq E P_{h} \\
0, & \text { otherwise }
\end{array}\right.
$$

The graded mean integration representation (Chen and Chen, 2001) is then as follows.

$$
G(E P)=\frac{E P_{l}+4 E P_{m}+E P_{h}}{6}
$$

With this value, we can find a defuzzified representative of the unique fuzzy number. Further, for the optimal condition, the expert can assign various scenarios of demand information and get the graded mean representation for each scenario of demand respectively. Then we can find the optimal condition for the problem.

The algorithm for the solution is as follows.

Algorithm (Fuzzy Linear Model for Supply Chain Contract)

Step 0 Membership function

Assign fuzzy probabilities to the demand information by experts

Make the membership function of demand information
Step 1 Initialize parameters

Set all parameters such as prices and costs

Step 2 Solve the Linear Program

Get solutions and objective values for all scenarios

Step 3 Calculate graded mean integration representation

Get $G(E P)$

Repeat Step 2 and Step 3 for all levels of demand information

Step 4 Solution

Decide the solution from the results

The algorithm generates the estimates of optimal solution. We focus on the maximization of the expected profits of the buyer and supplier. The demand information in period 2 is the fuzzy random variable.

\section{Experimental results}

This section presents the implementation and the experimental results for the buyer and supplier's problem. The solution algorithms for 
Table 2. Results of the buyer problem

\begin{tabular}{|c|c|c|c|c|}
\hline Levels & $E P_{l}$ & $E P_{m}$ & $E P_{h}$ & $G(E P)$ \\
\hline 1 & 6500 & 10500 & 14900 & 10566.67 \\
\hline 2 & 7292 & 10500 & 12628 & 10320.00 \\
\hline 3 & 8364 & 10500 & 14764 & 10854.67 \\
\hline 4 & 9428 & 10500 & 11564 & 10498.67 \\
\hline 5 & 9828 & 10500 & 10896 & 10454.00 \\
\hline 6 & 9300 & 10500 & 12500 & 10633.33 \\
\hline
\end{tabular}

the buyer and the supplier were implemented by $\mathrm{C}+$ and CPLEX in $\mathrm{C}++$ was used to solve the problems. The dataset were randomly generated for period 1 and 2 .

\subsection{Experiment of the buyer problem}

The parameters of prices and costs are as follows.

$h_{1}=h_{2}=0.5, s_{1}=s_{2}=12, r_{1}=r_{2}=6$, $p_{1}=p_{2}=8, e_{1}=8, o_{1}=1.5, v=4$, and $X_{\text {max }}=10000$

The demand are randomly generated some levels with three of scenarios: low, medium, and high. The data set is listed in Table 1. Table 1 shows the six levels of demand with three scenario values.
We set the medium value of demand 1000 and the other values of low and high demand are randomly generated. With this information, the membership function of demand can be generated by the same way of (31) that for the expected profits.

Table 2 presents the solution of the expected profits for each level with three scenarios. Using three scenario solutions, the graded mean integration representations are calculated. With these values, the buyer can make a decision of order quantities and amount of options to buy at the beginning of period 1 .

6.2 Experiment of the supplier problem

The parameters of the supplier problem are

Table 3. Results of the supplier problem.

\begin{tabular}{|c|c|c|c|c|}
\hline Levels & $E P_{l}$ & $E P_{m}$ & $E P_{h}$ & $G(E P)$ \\
\hline 1 & 15375.0 & 13250 & 10665.0 & 13173.3 \\
\hline 2 & 14954.3 & 13250 & 12119.5 & 13345.6 \\
\hline 3 & 14384.8 & 13250 & 10984.8 & 13061.6 \\
\hline 4 & 13819.5 & 13250 & 12684.8 & 13250.7 \\
\hline 5 & 13568.8 & 13250 & 13002.5 & 13261.9 \\
\hline 6 & 13775.0 & 13250 & 12300.0 & 13179.2 \\
\hline
\end{tabular}


as follows.

$v^{f}=5, v^{r}=2, v^{l}=4, t=4, o_{1}=1.5$, $e_{1}=8, \quad p_{1}=p_{2}=8, \quad c_{1}=3, \quad w_{1}=4$, $w_{2}=3, \quad h_{1}^{f}=h_{2}^{f}=0.25, \quad h_{1}^{r}=h_{2}^{r}=0.125$ and $I_{2}^{b}=0$

Table 3 shows the results of the expected profits for six levels with three different scenarios. The graded mean integration representations are also calculated with the results.

In the supplier problem, the demand of the buyer problem in Table 1 is used. Some parameters in the supplier model are the same meaning as the buyer problem.

Order quantities of finished products and the amount of options to purchase or to exercise from the buyer are used from the results of the buyer problem.

From the results in section 6.1 and 6.2, the buyer and the supplier aim to achieve their own maximum profits which may be the local optimum in the supply chain.

Considering the coordination, if we depict the profits with $G(E P)$ of the buyer, the supplier, and the sum of two profits against each parameter such as option price or exercise price, the area or point of the maximal total profits can be the global optimum in the supply chain. If we extend the experiment with describing the distribution of the profits by exercise or option price, we can find the area or point for the efficient frontier.

\section{Conclusion}

This paper suggested a supply chain contract model with flexible options and fuzzy random demand. Fuzzy set theory can be used to make the model for the supply chain contract between the buyer and the supplier with flexible options when the probability distribution of demand is not appropriate.

In real world, the data for deriving the probability distribution in stochastic programs is not always available. Even if the data is available, the probability distribution may not be accurate. Therefore, it is difficult to make the successful stochastic programming model with this vague information. In this situation, fuzzy set theory can be used to represent the demand values. An important part is the measure of decision or defuzzification when we use the fuzzy set theory. This paper adopted the graded mean integration representation method as the one of methods.

In the decentralized supply chain environment, the buyer and the supplier aimed to achieve their own optimal solutions, which results in the local optimal or poor solutions. The supply chain contract can reduce the conflict between two members. The option in this paper plays an important role to reduce or add order quantities at the second period. The contract was implemented by the fuzzy linear programming model. The experimental results have compared with various levels of input data set. We also have investigated the expected profits with the 
measure of the graded mean integration representation.

In future, it is a good issue to investigate the sensitivity of parameters for the change of solutions. We can also apply the integration technique of fuzzy set theory to integrate the membership functions of the objective function and constraints. The model of the problem can be extended to the trapezoidal fuzzy number for the supply chain contract or other applications. If the supply chain contract model proposed in this paper is integrated with Collaborative Planning, Forecasting, and Replenishment (CPFR), the efficiency can be improved.

\section{References}

문태수, 강성배, “환경, 조직, 정보시스템 요인이 공급사슬관리 $(\mathrm{SCM})$ 시스템의 균형적 기업 성과(BSC)에 미치는 영향 연구," 정보시스템연구, 제 17 권, 제 2 호, 2008 , pp.1-26.

서창교, 박종채, 정은희, "공급체인관리시스템 도입에 영향을 주는 요인," 정보시스템 연구, 제12권, 제2호, 2003, pp.165-187. 조남재, 윤재환, 정진관, “공급자-구매자 조직간 특성과 $\mathrm{EDI}$ 활용수준이 $\mathrm{SCM}$ 성과에 미 치는 영향에 관한 연구," 정보시스템연 구, 제16권, 제4호, 2007, pp.165-187.

Arshinder, K. A., Deshmukh, S. G., "Coordination in Supply Chains: An Evaluation Using Fuzzy Logic,"
Production Planning and Control, Vol. 18, No.5, 2007, pp.420-435.

Bjork, K. M., Carlsson, C., "The Outcome of Flexible Lead Times on the Distributors," System Sciences, HICSS '05 Proceedings of the 38th Annual Hawaii International Conference on 2005, 2005, pp.81a-81a. Cachon, G., Supply Chain Coordination with Contracts, Handbooks in Operations Research and Management Science: Supply Chain Management, North Holland, 2003.

Chen, S. H., "Operations of Fuzzy Numbers with Step Form Membership Function Using Function Principle," Information Sciences, Vol.108, No.1-4, 1998, pp.149-155.

Chen, S. H., Wang, C. C., "Representation, Ranking, Distance and Similarity of Fuzzy Numbers with Step Form Membership Function Using K-preference Integration Method," Annual Conference of the North American Fuzzy Information Processing Society-NAFIPS, 2001, pp.801-806.

Chen, S. J., Chen, S. M., "A New Method to Measure the Similarity between Fuzzy Numbers," 10th IEEE International Fuzzy Systems Conference, 2001, pp.1123-1126.

Chen, S. P., Ho, Y. H., "Analysis of the Newsboy Problem with Fuzzy Demands and Incremental Discounts," International 
Journal of Production Economics, Vol.129, No.1, 2011, pp.169-177.

Delft, C., Vial, J. P., "A Practical Implementation of Stochastic Programming: An Application to the Evaluation of Option Contracts in Supply Chains," Automatica, Vol.40, No.5, 2004, pp.743-756.

Dutta, P., Chakraborty, D., Roy, A. R., "A Single-Period Inventory Model with Fuzzy Random Variable Demand," Mathematical and Computer Modelling, Vol.41, No.8-9, 2005, pp.915-922.

Frascatore, M. R., Mahmoodi, F., "Long-Term and Penalty Contracts in a Two-Stage Supply Chain with Stochastic Demand," European Journal of Operational Research, Vol.184, No.1, 2008 pp.147-156.

Hall, J., Fu, G., Lawry, J., "Imprecise Probabilities of Climate: Aggregation of Fuzzy Scenarios and Model Uncertainties," Climate Change, Vol.81, No.3-4, 2007, pp.265-281.

Hu, Q., Kumar, A.; Shuang, Z., "A Bidding Decision Model in Multiagent Supply Chain Planning," International Journal of Production Research, Vol.39, No.15, 2001, pp.3291-3301.

Li, X., Zhao, Z., "Supply Chain Real Time Coordination Method Based on Buyback Contract with Fuzzy Random Demand," IEEE International Conference on Fuzzy
Systems, Sheraton Vancouver Wall

Centre Hotel, 2006, pp.1543-1549.

Peng, Y., Chen, H., "Measuring Supply Chain Flexibility and Selecting Supplier based on Supply Contract," Services Systems and Services Management, Proceedings of ICSSSM '05. International Conference, 2005, pp.669-673.

Petrovic, D., Roy, R., Petrovic, R., "Modelling and Simulation of a Supply Chain in An Uncertain Environment," European Journal of Operational Research, Vol.109, No.2, 1998, pp.299-309.

Sanders, I., Batty, W. J., Probert, S. D., Hagino, K., Aida, S., "Supply of, and Demand for, A Resource: Fuzzy Logistical Optimisation Technique," Applied Energy, Vol.46, No.4, 1993, pp.285-302. Sang, S.J., Zhang, Q., Wu, J.Z., "Return Contract of Supply Chain with Fuzzy Continuous Demand," Journal of Beijing Institute of Technology (English Edition), Vol.19, No.1, 2010, pp.115-120.

Simchi, D., Kaminsky, P., Designing and Managing the Supply Chain: Concepts, Strategies, and Case Studies, $2^{\text {nd }} \mathrm{ed}$, McGraw-Hill, 2003

Wang, J., Zhao, R., Tang, W., "Supply Chain Coordination by Revenue-Sharing Contract with Fuzzy Demand," Journal of Intelligent and Fuzzy Systems, Vol.19, No.6, 2008, pp.409-420.

Wang, J., Zhao, R., Tang, W., "Supply Chain 
Coordination by Single-Period and Long-Term Contracts with Fuzzy Market Demand," Tsinghua Science and Technology, Vol.14, No.2, 2009, pp.218-224.

Xiong, H., Chen, B., Xie, J., "A Composite Contract based on Buy Back and Quantity Flexibility Contracts," European Journal of Operational Research, Vol.210, No.3, 2011, pp.559-567.

Zimmermann, H. J ., Fuzzy Set Theory and Its Applications, $2^{\text {nd }}$ ed, Kluwer Academic Publishers, 1991.
김기태(Kim, $\mathrm{Gi}-\mathrm{Tal})$

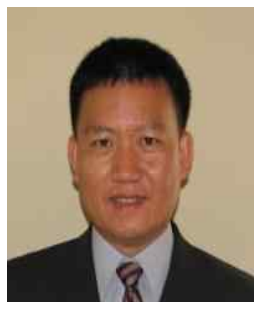

한양대학교 산업공학과에 서 학사, 서울대학교 공과대학 원에서 석사, 미국 Kansas State University 산업공학과에서 박 사학위를 받고, 현재 Kansas State University 산업공학과 연 구원으로 재중 중이다. 주요관 심분야는 Optimization, Support Vector Machine, Supply Chain Management, Analytics 등에 관심을 가 지고 있다.

박준철(Park, Jun-Chel)

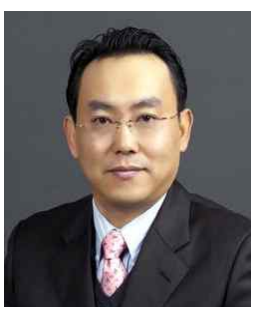

대구대학교 경영학에서 학 사, 한국외국대학교 경영정보 대학원 경영정보학과에서 석 사, 대구대학교 대학원 경영학 과에서 박사학위를 받고, 현재 강릉원주대학교 산업정보경영 공학과 부교수로 재직 중이다. 주요관심분야는 e-business, 인터넷 소비자행동, 기술 가치평가 등에 관심을 가지고 있다. 
<국문초록>

\title{
모호한 수요정보에서의 공급망 계약 모델
}

\author{
김기태 · 박준철
}

본 논문은 고객의 수요정보에 대해 모호한 정보를 가진 공급자와 구매자 사이의 공급망 계약에 관한 것을 다루고 있는 것으로, 고객 수요에 대한 불확실성은 확률적 프로그래밍 모델에서 공식적으로 다루어져왔다. 확률적 프로그램의 한 가지 핵심적인 가정은 널리 알려져 있는바와 같이 수요에 대한 확률분포가 알려져 있다는 것이다. 그럼에도 불구하고 만약 수요에 대한 정보가 모호하거나 정확하지 않다면 수요에 대한 확률분포가 정확하지 않다는 점이다. 이런 상황에서 퍼지 이론은 수요정보를 나타내는데 유용하다고 할 수 있다. 본 논문은 퍼지 랜덤 수요변수들을 분산시스템의 공급망 계약에서 다루고 있다. 이 계약은 구매자의 주문량을 조정하는 옵션을 이용한다. 본 연구는 퍼지 랜덤 변수들을 GMIR(Graded Mean Integration Representation)을 이용하여, 알고리즘을 통해 구현함으로써 실증적 결과 값을 제시하고 미래 연구의 확장 가능성을 제시하고 있다.

Key words : Supply Chain Contract, Fuzzy Set Theory, Vague Information, Quantity Flexibility Contract, Graded Mean Integration Representation

* 이 논문은 2012년 4월 12일 접수되어 1차수정(2012년 6월 14일)과 2차수정(2012년 6월 26일)을 거 쳐 2012년 6월 27일 게재 확정되었습니다. 